\title{
Risco de alagamentos influenciados por fatores ambientais em zonas urbanas de Macapá e Santana/AP
}

O sistema de drenagem de bacias hidrográficas urbanas tem sido negligenciado como dimensão do saneamento básico na Amazônia. Apesar de sua notável relevância sanitária, é frequentemente correlacionado com a potencialização de alagamentos, podendo agravar vários indicadores sanitários, ambientais e de saúde pública, especialmente na região do estuário amazônico, quando eventos climáticos extremos de precipitação ocorrem em consonância com elevações máximas das marés. O objetivo da pesquisa é quantificar o risco preliminar de alagamento de setores urbanizados das duas principais cidades do Estado do Amapá, Macapá e Santana. Especificamente, delinear cenários atuais e futuros para gerar subsídios ao planejamento dos sistemas de drenagem urbana e gestão das águas pluviais. Os procedimentos metodológicos foram os seguintes: a) coleta de dados na Coordenadoria Estadual e Municipal de Defesa Civil de Macapá e Santana (CEDEC); b) processamento dos dados, revisão da literatura, definição preliminar de risco e confecção de mapas temáticos utilizando o Sistema de Informação Geográfica QGIS; c) visita de campo para aferição in loco, identificação de impactos secundários em período chuvoso e validação dos dados geográficos disponibilizados pela CEDEC. Os principais resultados foram: mapeamento das zonas de risco preliminar em 28 setores de Macapá, com a seguinte classificação: 4 (14.29\%) de baixo, 7 (25.0\%) de médio e 17 $(60.71 \%)$ de alto risco de alagamento. Em Santana foram mapeados 6 setores: 2 (33.33\%) de médio e $4(66.67 \%)$ de alto risco de alagamento. Conclui-se que o risco preliminar de alagamento em período chuvoso, associado com aglomerados subnormais no entorno de "áreas de ressaca", é potencializado pelas elevações de marés de sizígia do rio Amazonas, apresentando similaridades em ambas as cidades frente aos problemas de gestão das águas pluviais. Os mapas de riscos preliminares apresentados podem ser extremamente úteis para políticas públicas e planejamento urbano, pois favorece a análise de contingenciamento e ordenamento territorial.

Palavras-chave: Alagamentos; Risco Preliminar; Planejamento Urbano; Saneamento Básico.

\section{Risk of flooding influenced by environmental factors in urban areas of Macapá and Santana/AP}

\begin{abstract}
The drainage system of urban watersheds has been neglected as a dimension of basic sanitation in the Amazon. Despite its remarkable sanitary relevance, it is often correlated with the potentiation of flooding, which can aggravate several sanitary, environmental and public health indicators, especially in the Amazon estuary region, when extreme precipitation weathe events occur in line with maximum tidal elevations. The objective of the research is to quantify the preliminary risk of flooding of urbanized sectors of the two main cities of the State of Amapá, Macapá and Santana. Specifically, outline current and future scenarios to generate subsidies for the planning of urban drainage systems and stormwater management. The methodological procedures were as follows: a) data collection at the State and Municipal Civil Defense Coordination of Macapá and Santana (CEDEC); b) data processing, literature review, methodological procedures were as follows: a) data collection at the State and Municipal Civil Defense Coordination of Macapá and Santana (CEDEC); b) data processing, literature review,
preliminary definition of risk and preparation of thematic maps using the QGIS Geographic Information System; c) field visit for on-site measurement, identification of secondary impacts in preliminary definition of risk and preparation of thematic maps using the QGIS Geographic Information System; c) field visit for on-site measurement, identification of secondary impacts in
rainy season and validation of geographic data provided by CEDEC. The main results were: mapping of the preliminary risk zones in 28 sectors of Macapá, with the following classification: 4 $(14.29 \%)$ low, $7(25.0 \%)$ medium and $17(60.71 \%)$ high risk of flooding. In Santana, 6 sectors were mapped: $2(33.33 \%)$ and $4(66.67 \%)$ high risk of flooding. It is concluded that the preliminary risk of flooding in rainy season, associated with subnormal clusters around "hangover areas", is enhanced by the elevations of sygy tides of the Amazon River, presenting similarities in both cities in the face of stormwater management problems. The preliminary risk maps presented can be extremely useful for public policies and urban planning as it favors contingency analysis and spatial planning.
\end{abstract}

Keywords: Flooding; Preliminary Risk; Urban Planning; Basic Sanitation.

Topic: Engenharia de Recursos Hídricos

Reviewed anonymously in the process of blind peer.

Taís Silva Sousa (iD

Universidade Federal do Amapá, Brasil http://lattes.cnpq.br/2341265184565372 http://orcid.org/0000-0003-3258-4621

taisousa155@gmail.com

Helenilza Ferreira Albuquerque Cunha (iD) Universidade Federal do Amapá, Brasil http://lattes.cnpq.br/3443290397582063 http://orcid.org/0000-0001-7101-9305

helenilzacunha@gmail.com

Alan Cavalcanti da Cunha (iD)

Universidade Federal do Amapá, Brasil http://lattes.cnpq.br/2181817533284030

http://orcid.org/0000-0002-1846-9486

alancunha12@gmail.com
Received: 03/04/2021

Approved: 26/04/2021
Referencing this:

SOUSA, T. S.; CUNHA, H. F. A.; CUNHA, A. C.. Risco de alagamentos influenciados por fatores ambientais em zonas urbanas de Macapá e Santana/AP. Revista Ibero Americana de Ciências Ambientais, v.12, n.4, p.245-259, 2021. DOI: http://doi.org/10.6008/CBPC21796858.2021 .004 .0021 


\section{INTRODUÇÃO}

A drenagem é um equipamento urbano de grande importância para o saneamento básico e planejamento das cidades, pois atua diretamente no controle de inundações e alagamentos (CANHOLI, 2005; SANTOS et al., 2019; BOHNENBERGER et al., 2019; SABÓIA et al., 2017). Sua importância é reconhecida principalmente em países desenvolvidos, que utilizam estes sistemas de drenagem como mecanismos de bem-estar social (PROMINSKI et al., 2017).

No Brasil, apesar de previsto na Política Nacional de Saneamento Básico (Lei no 11.445/07), atualizada pelo novo marco legal do saneamento (Lei no 14.026/2020), a drenagem urbana ainda é um eixo pouco estudado e valorizado (BRASIL, 2007; BRASIL, 2020). De acordo com o Sistema Nacional de Informações sobre Saneamento-SNIS (2019), cerca de 45\% dos municípios brasileiros não possuem sistemas exclusivos de drenagem. Isto é, a maior parte utiliza sistemas unitários (mesma rede para drenagem e esgoto) ou não possuem nenhum tipo de sistema de drenagem. Este cenário torna-se ainda mais preocupante na região norte do país, que apresenta o maior índice de municípios com ausência de serviços de drenagem, cerca de $45.8 \%$ (SNIS, 2019).

Macapá e Santana são os municípios mais populosos e importantes do estado do Amapá. Suas características costeiro-amazônicas as definem como cidades de grandes potenciais hídricos, marcadas por planícies inundáveis (BASTOS, 2010; SANTOS, 2016). Isto faz com que a bacia hidrográfica local seja influenciada por processos hidrodinâmicos e sazonais, ou seja, quando há coincidência entre eventos de chuvas intensas na bacia e efeitos de marés de sizígia, o risco de alagamento e inundações aumenta (SANTOS, 2016; CUNHA et al., 2018; ABREU et al., 2020). Isto ocorre, por esses municípios apresentarem infraestrutura de drenagem urbana deficiente, principalmente pela falta de manutenção preventiva e investimentos no setor.

Dessa forma, a pesquisa busca responder ao seguinte problema: qual o risco de alagamento e quais são os fatores influenciadores nos núcleos urbanos de Macapá e Santana? Para responder a esta questão, duas hipóteses foram testadas: a) O risco preliminar de alagamento está relacionado com a qualidade sanitária do ambiente, isto é, quanto mais precária é a área maior é a tendência do risco; b) O sistema de drenagem existente é deficitário, mas pode ser influenciado por fatores ambientais e infraestruturais responsáveis pela intensificação de inundações urbanas, comprometendo os indicadores de saneamento e principalmente a qualidade de vida da população (SOUSA et al., 2019).

Portanto, o presente estudo objetiva definir o risco preliminar de alagamento de setores urbanizados de Macapá e Santana e seus potenciais fatores geradores, delineando o cenário atual de drenagem desses municípios. Além disso, identificar os bairros mais afetados pelos alagamentos, a partir das características físicas e ambientais da bacia de drenagem, verificando in loco (estudo de caso) alguns dos impactos ambientais decorrentes da deficiência do sistema de drenagem urbana.

Este trabalho tem relevância cientifica e socioambiental porque identifica e propõe soluções que valorizem a importância da gestão das águas pluviais integrada aos ecossistemas costeiros amazônicos, 
estabelecendo uma conexão da ecologia com a proteção das cidades por eventuais alagamentos (PROMINSKI et al., 2017). As análises propositivas são relevantes para evitar ou contornar potenciais fatores responsáveis pela produção de alagamentos urbanos, servindo como subsídio e referência em cenários de riscos, contribuindo para o planejamento urbanístico e políticas públicas dos dois municípios.

\section{MATERIAIS E MÉTODOS}

\section{Área de estudo}

A pesquisa foi realizada na região norte do Brasil, abrangendo as cidades mais populosas do Amapá, Macapá e Santana (Figura 1), localizadas a sudeste do estado. Macapá é a capital e possui população estimada de 512.902 habitantes, enquanto Santana possui população estimada de 123.096 habitantes (IBGE, 2020).

Os munícipios são majoritariamente drenados pela bacia hidrográfica do Igarapé da Fortaleza. Esta bacia possui padrões de drenagem dendrítica, com seu canal principal conectado ao Canal Norte do Rio Amazonas (ABREU et al., 2020) cujos sistemas de drenagem menores conectam-se até as áreas úmidas, locais de importância ecológica e que sofrem constante pressão antrópica, denominados localmente como "ressacas" (BASTOS, 2010; SANTOS, 2016).
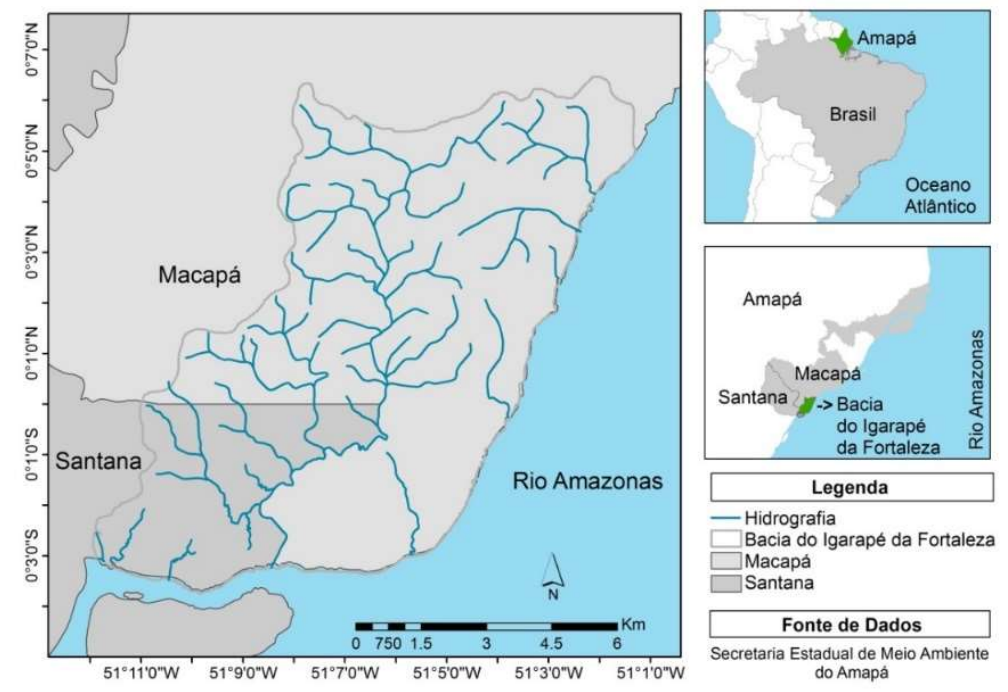

Figura 1: Bacia hidrográfica do Igarapé da Fortaleza limitada a leste pelo rio Amazonas e zona urbana de Macapá e Santana.

Macapá e Santana (Figura 1) possuem características do bioma amazônico, apresentando uma região costeira e presença de planícies inundáveis. O clima predominante é quente e úmido, com $80 \%$ da precipitação concentrada no período chuvoso (dezembro/agosto). Nesses meses é comum ocorrerem casos de alagamentos e inundações nessas cidades. Estes eventos ocorrem principalmente devido à ausência de um sistema de drenagem eficiente e a influência da dinâmica das marés semidiurnas ao longo do canal principal e dos afluentes da bacia hidrográfica (BASTOS, 2010; CUNHA et al., 2018; ABREU et al., 2020). 


\section{Obtenção e processamento de dados}

\section{Identificação dos setores de risco}

Os desastres ambientais são gerenciados localmente pela Coordenadoria Estadual e Municipal de Defesa Civil (CEDEC). A CEDEC é o órgão responsável por criar mecanismos assistencialistas de prevenção e suporte técnico para a sociedade em caso de incidentes ou sinistros relacionados com eventos extremos envolvendo as águas pluviais na bacia. Assim, os trabalhos primários são desenvolvidos por este órgão para facilitar a gestão das cidades durante a ocorrência de eventos extremos, dentre os quais o mapeamento e a identificação de áreas potenciais a riscos de alagamentos e inundações (BRASIL, 2007).

De acordo com as diretrizes dos órgãos competentes da área (Ministério das Cidades e Instituto de Pesquisas Tecnológicas), cada município deve dispor de relatório próprio (BRASIL, 2007). Porém, a atualização dos dados ao longo do tempo depende de recursos humanos especializados e também recursos financeiros (BRASIL, 2007). Por isso, muitas cidades têm lapsos temporais quando analisadas suas informações, como é o caso de Macapá e Santana (SOUSA et al., 2019).

Os últimos registros disponíveis sobre setores de risco em Macapá datam de 2018, enquanto os de Santana datam de 2012. Estes dados são os que foram utilizados nessa pesquisa. Contudo, a metodologia empregada nos dois relatórios é semelhante, diferindo somente nas respectivas datas que cada um foi elaborado. Estes registros consistem na identificação de áreas que constantemente alagam em ambas as cidades, utilizando-se de imagens de satélite dispostos no programa Google Earth e visitas de campo junto à CEDEC e CPRM (Serviço Geológico do Brasil) com o objetivo de obter informações e conhecimento sobre a área de estudo (CEDEC, 2018).

Dessa forma, foram delimitados oficialmente os setores de risco das duas maiores cidades do Estado do Amapá. Assim, após a análise do relatório de cada município, foi criado um arquivo em formato Shapefile com os respectivos setores urbanos, o que permitiu manipular os dados em Sistemas de Informações Geográficas - SIG. A elaboração dos Shapefiles e outras análises foram feitas no software Qgis versão 3.8 .1 (2019).

\section{Classificação dos setores de risco}

Para classificação do grau de risco preliminar a alagamentos foi utilizado dois critérios do Ministério das Cidades e Instituto de Pesquisas Tecnológicas: a) Processo Hidrológico $\left(C_{1}, C_{2}, C_{3}\right)$ e b) Vulnerabilidade $\left(V_{1}, V_{2}\right)$ (BRASIL, 2007). Essa metodologia objetiva subsidiar as análises de risco das cidades brasileiras e é difundida e aplicada em várias pesquisas (RODRIGUES et al., 2016; LIMA, 2016; HORA et al., 2009).

O processo Hidrológico foi analisado com o auxílio das variáveis fisiográficas (Tabela 1) da bacia do Igarapé da Fortaleza (BASTOS, 2010), análises com dados geográficos de drenagem natural e mapeamento de ressacas (TAKIYAMA et al., 2012), pois estes mecanismos podem refletir e influenciar no comportamento hidrológico da bacia, e portanto, defini-lo. 
Tabela 1: Índices fisiográficos da Bacia Hidrográfica do Igarapé da Fortaleza.

\begin{tabular}{|c|c|c|}
\hline Índice & Valor/Equação & Observações \\
\hline Área $\left(\mathrm{Km}^{2}\right)$ & 190.82 & \\
\hline Perímetro (km) & 66.06 & \\
\hline $\begin{array}{l}\text { Coeficiente } \\
\text { compacidade }\end{array}$ & $\begin{array}{l}K c=0.28 \cdot \frac{P}{\sqrt{A}} \\
=0.28 \cdot \frac{66.053}{\sqrt{190.823}}=1.34\end{array}$ & $\begin{array}{l}\text { O parâmetro Kc é importante para medir a tendência ou suscetibilidade } \\
\text { da bacia sujeita a fenômenos de enchentes e/ou alagamentos. }\end{array}$ \\
\hline Fator de forma & $\begin{array}{l}K f=\frac{A}{L^{2}}=\frac{190.823}{64^{2}} \\
=0.046\end{array}$ & $\begin{array}{l}\text { O parâmetro } K f \text { é importante quando se quantifica a suscetibilidade (ou } \\
\text { resiliência) das bacias às enchentes ou alagamentos. }\end{array}$ \\
\hline $\begin{array}{l}\text { Comprimento do Rio } \\
\text { Principal }(\mathrm{Km})\end{array}$ & 27.52 & \\
\hline $\begin{array}{l}\text { Comprimento de todos os } \\
\text { rios da bacia }(\mathrm{Km})\end{array}$ & 158.06 & Adimensional \\
\hline $\begin{array}{l}\text { Densidade de drenagem } \\
\text { da bacia }(\mathrm{Dd})\left(\mathrm{Km} / \mathrm{Km}^{2}\right)\end{array}$ & $\begin{array}{l}D d=\frac{\sum l}{A}=\frac{158.06}{190.823} \\
=0.828\end{array}$ & $\begin{array}{l}\text { O valor relativamente baixo de } D d \text {, que resultou em } 0.828 \mathrm{Km} / \mathrm{Km}^{2} \text {, } \\
\text { designa que a bacia apresenta drenagem "pouco ramificada" com } \\
\text { corpos hídricos perenes e bem definidos. }\end{array}$ \\
\hline
\end{tabular}

Fonte: Adaptado de Bastos (2010).

Na tabela 1 o coeficiente de compacidade $(K c)(1.34)$ e fator de forma $(K f)(0.046)$ indicam, respectivamente, que a bacia do Igarapé da Fortaleza, de forma geral, é hidrologicamente pouco sujeita à inundação (por precipitação). Neste caso, o processo hidrológico estimado é do tipo $C_{1}$ que se refere às bacias cujos alagamentos e inundações são resultantes de processos normais que ocorrem em planícies fluviais (BRASIL, 2007).

Entretanto, quando a bacia do Igarapé da Fortaleza é analisada de forma mais detalhada em algumas áreas (zona leste principalmente), percebe-se claramente uma potencial influência da dinâmica das marés semidiurnas que é vinculada com as áreas de "ressacas" (BASTOS, 2010; ABREU et al., 2020 ). O aspecto hidrográfico dos corpos hídricos costeiros caracteriza essas áreas como tipo $C_{2}$, que é mais suscetível à ocorrência de alagamentos e inundações que o processo $C_{1}$ (BRASIL, 2007).

Todavia nenhuma área se enquadrou na categoria $C_{3}$, que é característico de bacias onde ocorrem inundações com alta energia de escoamento e maior potencial destrutivo (BRASIL, 2007). Assim a bacia hidrográfica do Igarapé da Fortaleza se enquadra apenas nas tipologias de processo $C_{1}$ e $C_{2}$.

A vulnerabilidade da ocupação urbana foi verificada com o auxílio de ortofotos da Base Cartográfica Digital Contínua do Amapá (BCDCA, 2015) e análises geoespaciais no software Qgis. Assim, a vulnerabilidade pode ser categorizada como alta $\left(\mathrm{V}_{1}\right)$ ou baixa $\left(\mathrm{V}_{2}\right)$ dependendo do padrão das construções habitacionais. $O$ indicador $V_{1}$ é adotado para locais que predominantemente possuem construções de madeiras e outros materiais com baixa capacidade de resistência, enquanto o indicador $V_{2}$ se refere às áreas onde predominam construções em alvenaria com boa capacidade de resistir aos impactos dos processos hidrológicos (BRASIL, 2007).

Após a análise e definição de cada critério, o grau preliminar do risco de alagamento foi determinado através do arranjo das variáveis relacionadas com os processos hidrológicos e vulnerabilidade, como apresentado na tabela 2. Posteriormente, mapas temáticos foram produzidos no Qgis, fazendo a correspondência de cada grau de risco a uma cor específica, para facilitar a análise e compreensão. $O$ baixo 
risco é equivalente nos mapas a cor azul, o médio risco a cor amarela, e o alto risco a cor vermelha, como poderá ser observado mais adiante nos resultados.

Tabela 2: Grau de risco preliminar segundo o arranjo entre cenários hidrológicos e vulnerabilidade das habitações.

\begin{tabular}{lll}
\hline & $C_{1}$ & $C_{2}$ \\
\hline$V_{1}$ & Médio (M) & Alto (A) \\
$V_{2}$ & Baixo (B) & Médio (M) \\
\hline
\end{tabular}

Fonte: Adaptado de Brasil (2007).

\section{Visita de campo e estudo de caso}

Visitas de campo nas duas cidades foram realizadas com o objetivo de validar os dados geográficos disponibilizados pela CEDEC e identificar possíveis impactos secundários. Assim, no mês de junho de 2020 (período chuvoso amazônico) foram visitados os setores de risco a alagamentos. A partir da análise geral, uma amostra de cada setor foi mapeada no GPS e então suas coordenadas determinadas como "pontos de alagamento". A espacialização dos dados, integração dos resultados e a produção de mapas foram feitas utilizando a plataforma Qgis.

Além disso, foi produzido um compilado de informações (metadados) sobre um caso de evento extremo de chuva ocorrido no município de Macapá, com base em fontes jornalísticas recentes. É importante destacar que o estudo de caso corrobora de forma realística e objetiva os resultados deste trabalho, favorecendo sua contextualização integrada com fatos e registros atuais.

\section{RESULTADOS}

\section{Setores de risco}

Apesar da bacia do Igarapé da Fortaleza ser pouco suscetível às inundações e alagamentos, algumas especificidades sanitárias e ambientais podem alterar este estado, como é o caso da influência de marés de sizígias e ocupação desordenada de aglomerados subnormais nas áreas de ressaca, causando uma série de impactos (SOUSA et al., 2019). De acordo com o relatório da CEDEC, Macapá possui 28 setores de risco (Figura 2a) e Santana 6 setores de risco (Figura 2b), cujas áreas são altamente vulneráveis aos desastres provenientes de alagamentos. Estes resultados são preocupantes, mesmo para os padrões de urbanização amazônicos (cidades de médio e pequeno porte) (CANHOLI, 2005).

Para o perímetro urbano de Macapá a classificação do grau de risco preliminar permitiu avaliar todas as áreas de risco de forma isolada. O resultado é mostrado na figura $2 a$, onde foram obtidos os seguintes resultados: 4 (14.29\%) setores de baixo risco preliminar (cor azul), 7 setores (25\%) de médio risco preliminar (cor amarela) e 17 (60.71\%) de alto risco preliminar (cor vermelha).

Nessa ordem percebe-se que a presença do alto risco preliminar é predominante na cidade, sugerindo riscos não somente ao bem estar social, mas também à saúde pública, qualidade do saneamento, ao meio ambiente e aos ecossistemas em geral. Além disso, dentre os 28 bairros de Macapá, 23 (82.14\%) foram tangenciados por alguma área de risco e apenas 5 bairros (17.86\%) não apresentaram sítios em risco.

Estes resultados sugerem uma maior atenção do poder público para gestão e prevenção de danos. 
Os bairros mais afetados pelos alagamentos são Central e Santa Inês, por estarem ambientalmente vinculados com lagos urbanos que drenam a cidade e o rio Amazonas, e influenciados por fatores hidrológicos sazonais e as marés semidiurnas (ABREU et al., 2020).

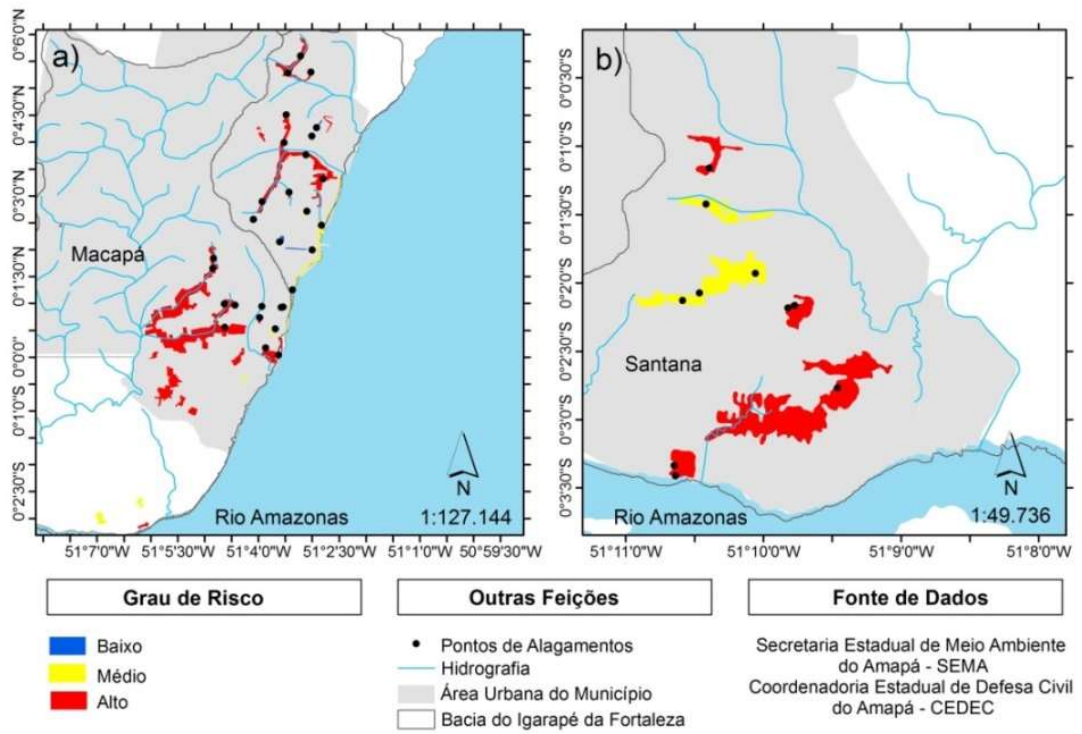

Figura 2: Áreas de Riscos a alagamentos. 2a- Núcleo urbano de Macapá; 2b- Núcleo urbano de Santana.

De modo similar, o risco preliminar identificado em Santana resultou na figura 2 b: 2 (33.33\%) setores de médio risco (cor amarela) e 4 (66.67\%) de alto risco (cor vermelha). Observa-se que em Santana também ocorre uma fração da área estudada com índice de alto risco. Isto pode estar associado com a localização geográfica das cidades, isto é, na posição de proximidade do setor sul da bacia hidrográfica em confluência com o rio Amazonas. Portanto, os dois municípios possuem as mesmas características ambientais, e sujeitas praticamente às mesmas influencias físicas, sejam a dinâmica dos eventos hidrodinâmicos (marés), sejam os mesmos fenômenos hidrometeorológicos extremos (precipitação) (ABREU et al., 2020).

Além disso, o crescimento acelerado e desordenado desses municípios, em simultaneidade com o baixo grau de infraestrutura do sistema de drenagem em áreas de planície inundáveis, parece estar contribuindo com o aumento nas áreas de alto risco. Tanto que, dentre os 14 bairros de Santana, 9 (64.28\%) possuem alguma área de risco, enquanto 5 (35.72\%) não possuem sítios em risco. Assim, os bairros mais afetados pelos alagamentos em Santana são os bairros Central e Remédios, especialmente em razão da conectividade e proximidade entre os canais de macrodrenagem e áreas de ressaca na cidade, além do nível de planejamento desses bairros.

\section{Pontos de alagamentos e impactos secundários}

Durante a visita de campo foram demarcados 29 pontos de alagamentos na cidade de Macapá, e 10 pontos em Santana. Estes pontos apresentam características típicas que podem exercer influência nos eventos de alagamento, com destaque para: a) proximidade ou inserção em áreas de ressacas ocupadas e ou urbanizadas, e que desequilibram o ciclo hidrológico natural e a qualidade ecológica intensificando os eventos de alagamentos; b) ocupação de áreas rebaixadas sem o planejamento adequado, dificultando o 
escoamento superficial das águas pluviais e provocando alagamentos; e c) proximidade com corpos hídricos ou canais de macrodrenagem e falta de saneamento básico.

Dessa forma, estes fatores representam os principais impactos secundários que tendem a ser potencializadores dos alagamentos, sendo facilmente identificados nesses setores. Observou-se na visita de campo, o acúmulo de resíduos sólidos nas vias urbanas, causador do entupimento de bueiros e tubulações, os quais facilitam ou intensificam os eventos de alagamentos, e potencialização de fontes pontuais e difusas de esgotos domésticos que oferecem maiores riscos a epidemias e impede o funcionamento eficaz do sistema de drenagem urbana.

\section{Estudo de caso - evento extremo de chuva em Macapá e verificação de alagamentos}

A cidade de Macapá é marcada no período chuvoso (dezembro/agosto) por diversos impactos de alagamento, principalmente os relacionados com a deficiência do sistema de drenagem urbana (BASTOS, 2010). Portanto, devido aos problemas de urbanização desorganizada, tanto em Macapá quanto em Santana, são também cada vez mais frequentes eventos de alagamentos e inundações em ambos os municípios. Por um lado, as intensidades crescentes das precipitações acarretam cada vez mais danos imediatos. Por outro lado, a longo prazo o problema tende a se expandir e intensificar, aumentando os riscos futuros à população local (SOUSA et al., 2019).

Como uma observação dos impactos e fatores que influenciam os alagamentos, é possível perceber na figura 3 uma situação de congestionamento do sistema de macrodrenagem na principal via que interliga a zona norte à zona sul da cidade de Macapá. Circunstâncias semelhantes também ocorrem em outros pontos da cidade, concentrando-se, sobretudo, nas áreas de risco preliminar identificadas na Figura 2.

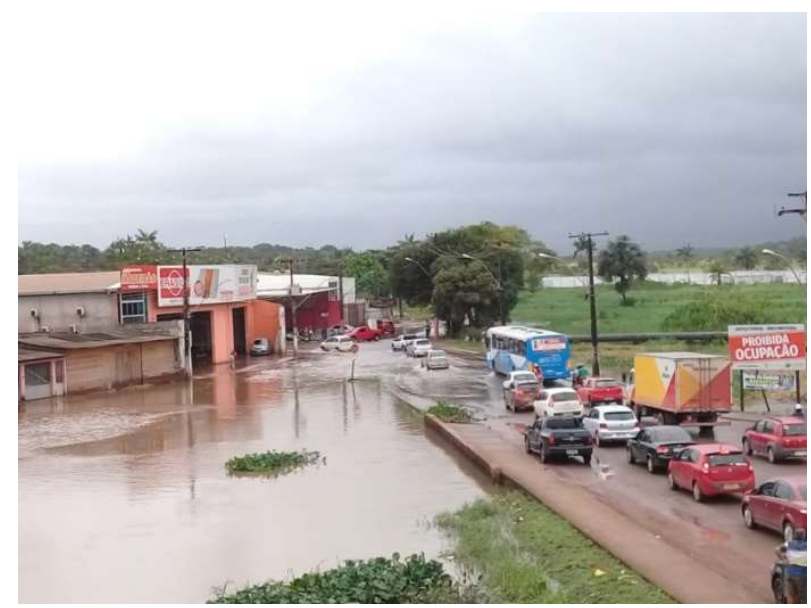

Figura 3: Exemplo de alagamento no núcleo urbano de Macapá.

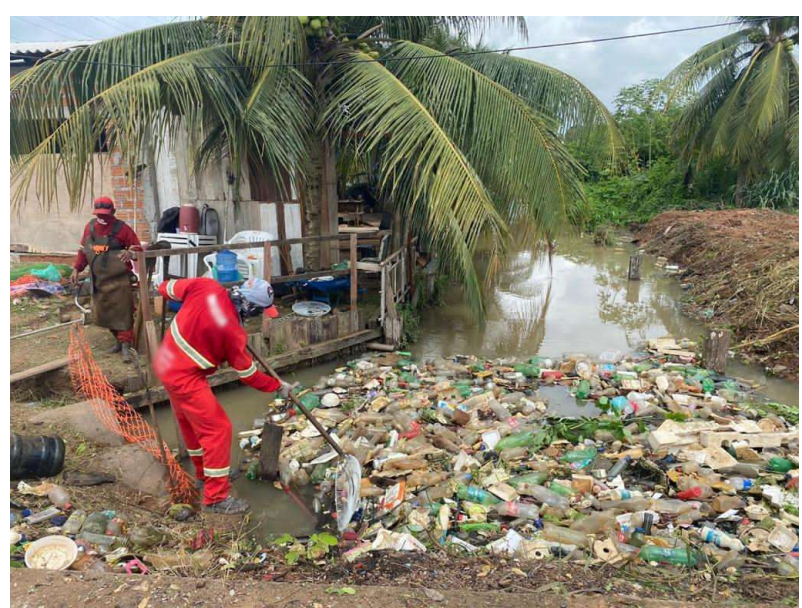

Figura 4: Desobstrução dos canais de macrodrenagem em Macapá. Fonte: PMM (2020).

Portanto, eventos de precipitações extremas, como ocorrido em 22 de novembro de 2020 estão se tornando mais frequentes. Neste, a precipitação diária máxima esperada era de 45 milímetros, entretanto, em menos de 1 hora de chuva, o município de Macapá registrou cerca de 74 milímetros, o que causou transtornos sérios à população e danos materiais de baixa escala (PMM, 2020). Uma das principais causas destes transtornos foi registrada pelo transbordamento do canal de macrodrenagem do Beirol que impactou 
a maior parte dos bairros do entorno (devido à elevação da maré) (Figura 4).

É importante frisar que o referido evento extremo foi também marcado pelas condições desfavoráveis no fornecimento de energia elétrica, que dificultou ações mais efetivas da defesa civil. Na ocasião, Macapá e mais 14 municípios do estado se encontravam em fase de blackout (METRÓPOLES, 2020).

Como ação remediadora e preventiva a Defesa Civil Municipal, associada com a Prefeitura Municipal de Macapá-PMM, realizaram a desobstrução no canal do Beirol (Figura 4) além de outros pontos considerados de risco na mancha urbana. É bom frisar que estas áreas já sofrem historicamente com transbordamento (PMM, 2020). Portanto, este é um exemplo claro da necessária integração da dimensão da gestão das águas pluviais e sistemas de drenagem com outras dimensões do saneamento (água, esgoto e resíduos sólidos), pois os resíduos sólidos despejados em locais inadequados (corpos d'água), além da ocupação desordenada, provoca o assoreamento e a obstrução dos canais de macrodrenagem, influenciando negativamente no fluxo das águas e aumentando, portanto, as chances de novos casos de alagamentos (Item 2, 4, 5 e 8 da tabela 3) (PMM, 2020; SOUSA et al., 2019).

\section{DISCUSSÃO}

\section{Integração das áreas de risco a alagamentos com variáveis socioambientais}

Na figura 2 observa-se que os setores mais próximos a áreas de ressaca ou corpos hídricos em geral tendem a apresentar graus de riscos mais elevados. Isto geralmente ocorre porque há uma significativa precariedade sanitária de vários indicadores das cidades do Estado do Amapá (SNIS, 2019). Assim, o saneamento básico em associação com as falhas frequentes do planejamento urbano em regiões topograficamente baixas das cidades, parece influenciar diretamente no agravamento dos eventos e consequentemente no aumento dos riscos de alagamento (CANHOLI, 2005; LOURENÇO et al., 2019). Historicamente, a oferta dos serviços sanitários não acompanha a expansão demográfica de Macapá e Santana (CHAGAS et al., 2016).

Esta situação não se restringe somente às cidades amazônicas, mas é a realidade de quase $80 \%$ da população brasileira (PMSB, 2016; ARAÚJO et al., 2019; BARROS, 2005). Por exemplo, no Brasil, São Paulo e Belo Horizonte, a urbanização acelerada e a falha no planejamento urbano são consideradas as principais causas do aumento de riscos a alagamentos (RODRIGUES et al., 2016; NUNES et al., 2018). Por isso a expansão urbana deve considerar as tecnologias que reduzam a intensidade desses desastres, como a utilização de sistemas de drenagem sustentável (CANHOLI, 2005; PROMINSKI et al., 2017; SILVA JUNIOR et al., 2017; PIACENTINI et al., 2020; ZUBELZU et al., 2020).

Um sistema de drenagem sustentável bem planejado e adequado às especificidades do local pode evitar uma série de eventos catastróficos (PROMINSKI et al., 2017). Alguns estudos científicos corroboram este fato (BATTEMARCO et al., 2018; MONTAGNA et al., 2019; ROCHA et al., 2018). Por exemplo, um caso que se assemelha com a realidade amapaense é o da cidade de Natal, a qual vem sofrendo com o aumento desordenado da população sem o devido aparato urbano, e se propõe a adoção de reservatórios de detenção 
e infiltração como técnica para reduzir os problemas de inundações na cidade (ROCHA et al., 2018).

Se aplicado corretamente as técnicas de gestão de águas pluviais e de sistemas de drenagem sustentável, por exemplo, em implementações sanitárias em Macapá e Santana, haveria uma significativa redução das áreas de risco de alagamentos e inundações. Remediações similares ocorreram no Brasil com resultados muito positivos na comunidade de Mandaqui (localizada ao redor do Córrego Mandaqui em São Paulo), que ao promover medidas de conservação para o canal de drenagem, apresentou melhorias no bemestar social e qualidade de vida das pessoas (TZORTZIS et al., 2016).

Como a oferta desses serviços de drenagem é muito baixa em Macapá, atendendo apenas $11,9 \%$ da área urbana, é comum que a população sofra principalmente no período chuvoso com problemas diretos e indiretos decorrentes dessa infraestrutura deficitária (PMSB, 2016; CANHOLI, 2005). Por exemplo, como observado na figura 2, há um padrão muito semelhante das áreas de risco preliminar entre Macapá e Santana.

Isso sugere que as condições sanitárias estão correlacionadas com a sazonalidade e questões hidroambientais (dependentes do ciclo hidrológico local), onde se percebe maior influência nas áreas de alto risco são as mais sujeitas às flutuações de marés (ABREU et al., 2020). Como resultado, é possível inferir que a população esteja ainda mais exposta nestes locais aos impactos negativos dos alagamentos também devido à vulnerabilidade sanitária e características ambientais dos diferentes bairros e situação precária de saúde pública (GROTT et al., 2018; VIEGAS et al., 2021) além do sistema de abastecimento de água extremamente frágil. Esse fato tem sido observado em outros estudos na literatura, corroborando esta informação (ABU et al., 2018; TEIXEIRA et al., 2018; LOURENÇO et al., 2019; MANSUR et al., 2018).

As zonas indicadas com cores mais "quentes" da figura 2 (vermelho), ocupam majoritariamente estas áreas costeiras ou conectadas a elas. Portanto, isto ocorre pela presença de aglomerados subnormais, ocupação desordenada dos núcleos urbanos e poucos investimentos no setor de saneamento básico, contribuindo com o aumento do grau de impermeabilização do solo, o que tende ao aumento dessas áreas de risco (tópicos 1, 2 e 6 da tabela 3) (ABREU et al., 2020; BASTOS, 2010; MORAIS et al., 2018). Assim, o contexto sanitário é refletido claramente e agravado pela quantidade alarmante de bairros afetados por alagamentos, sendo 82.14\% em Macapá e 64.28\% em Santana.

\section{Estudo de caso e sua relação com os impactos secundários dos alagamentos}

Durante a investigação, verificou-se que o agravamento dos alagamentos ocorreu de fato nas zonas críticas consideradas de alto risco (Figura 2). A tabela 3 explana os 15 principais fatores responsáveis pelos alagamentos e inundações nos núcleos urbanos, segundo o contexto da presente pesquisa. Uma interpretação sobre os impactos em Macapá e Santana foi feita com uso dos dados oficiais disponíveis. Este tópico, portanto, é uma síntese do estudo de caso do referido evento extremo de precipitação em Macapá, registrando-se as principais fontes secundárias (literatura) e primárias (visita de campo durante eventos de chuva). 
Tabela 3: Exemplos dos principais problemas de drenagem de Macapá e Santana. Na tabela, o termo "Sim" significa que o fator é responsável pela produção de inundações urbanas, e "Não" significa que não é responsável pela produção de inundações urbanas.

\begin{tabular}{|c|c|c|c|}
\hline $\mathrm{N}$ & Fator Responsável pela Produção de Inundações Urbanas & Macapá & Santana \\
\hline 1 & $\begin{array}{l}\text { Aumento gradativo do volume de escoamento superficial para o mesmo índice de precipitação, } \\
\text { tornando o sistema de drenagem obsoleto e incapaz de escoar as chuvas para as quais foi projetado } \\
\text { (quando existente). }\end{array}$ & Sim & Sim \\
\hline 2 & $\begin{array}{l}\text { Crescimento do volume de sedimentos nos canais drenadores, decorrente da ocupação irregular do } \\
\text { solo, sem controle da erosão e assoreamento dos leitos, com redução da capacidade de transporte da } \\
\text { água pelo sistema de drenagem. }\end{array}$ & Sim & Sim \\
\hline 3 & $\begin{array}{l}\text { Existência de Plano Diretor que não considera devida e efetivamente os aspectos da drenagem da } \\
\text { bacia (inclusive as marés). }\end{array}$ & Sim & Sim \\
\hline 4 & $\begin{array}{l}\text { Lançamento de resíduos sólidos e lixo nos córregos, igarapés e rios, galerias e canais, decorrente do } \\
\text { sistema deficiente de coleta, principalmente em zonas de muita pobreza ou de baixa renda (ressacas, } \\
\text { bairros periféricos, favelas, linhas costeiras, áreas irregularmente ocupadas, áreas de elevação, ou } \\
\text { ribeirinhas, etc.). }\end{array}$ & Sim & Sim \\
\hline 5 & $\begin{array}{l}\text { Falta de educação para o Saneamento Básico, principalmente em relação à dimensão drenagem, } \\
\text { evitando-se lançamento de resíduos sólidos em corpos d'água, dificultando seu escoamento. }\end{array}$ & Sim & Sim \\
\hline 6 & $\begin{array}{l}\text { Falta de investimentos para controlar cheias urbanas (planejamento e execução e manutenção de } \\
\text { obras civis). }\end{array}$ & Sim & Sim \\
\hline 7 & $\begin{array}{l}\text { Obsolescência de sistemas de drenagem urbana existente, resultante do aumento da vazão no tempo } \\
\text { e da falta de manutenção. }\end{array}$ & Sim & Sim \\
\hline 8 & $\begin{array}{l}\text { Problemas com obras mal executadas, galerias obstruídas, pontes com posicionamento inadequado } \\
\text { em relação à seção do rio, etc. }\end{array}$ & Sim & Sim \\
\hline 9 & $\begin{array}{l}\text { Falta de legislação própria para tratar de problemas de drenagem, ou quando existente, falta de } \\
\text { controle e fiscalização em relação às ocupações e obras irregulares. }\end{array}$ & Sim & Sim \\
\hline 10 & $\begin{array}{l}\text { Definição imprópria da área de abrangência de projetos de drenagem, muitas vezes transferindo } \\
\text { inundações de uma cidade para outra (não consideram o vínculo hidráulico entre duas cidades e na } \\
\text { mesma bacia - como é o caso do Igarapé da Fortaleza - Macapá e Santana). Às vezes as divisas } \\
\text { municipais não correspondem aos divisores de águas (problemas técnicos, gerenciais e até políticos). }\end{array}$ & Não & Sim \\
\hline 11 & Falta de informações hidrometeorológicas confiáveis para execução de projetos de drenagem urbana. & Não & Não \\
\hline 12 & $\begin{array}{l}\text { Falta de cadastramento de obras de drenagem existentes, tanto microdrenagem (bocas de lobo, redes } \\
\text { coletoras, etc.) quanto macrodrenagem (canais, reservatórios, etc.). }\end{array}$ & Sim & Sim \\
\hline 13 & $\begin{array}{l}\text { Inexistência de um órgão gestor e coordenador específico para drenagem urbana (evitar obras } \\
\text { incompatíveis ou que podem se prejudicar mutuamente numa mesma região). }\end{array}$ & Sim & Sim \\
\hline 14 & Inexistência de norma técnica para projetos de drenagem urbana numa mesma bacia hidrográfica. & Sim & Sim \\
\hline 15 & $\begin{array}{l}\text { Ocorrência de eventos hidrometeorológicos extraordinários, acima do risco assumido pela falha das } \\
\text { obras de drenagem. Pois as obras são dimensionadas em função da relação risco e custo, portanto, } \\
\text { mesmo as obras bem projetadas, devidamente executadas, estão sujeitas a falhas. }\end{array}$ & Sim & Sim \\
\hline
\end{tabular}

Fonte: Adaptado de Barros (2005).

Portanto, a ocupação irregular dos municípios associada ao grande volume de chuvas (muitas vezes acima volume esperado) dificulta o planejamento estratégico da drenagem, reduz sua capacidade de suporte para o gerenciamento das águas pluviais e aumenta a sedimentação dos canais de macrodrenagem (SOUSA et al., 2019; SNIS, 2019; MORAIS et al., 2018). Os itens 1, 2 e 15 da tabela 3 são corroborados diretamente pelo estudo de caso e também pela literatura. Na figura 2 é possível analisar as áreas mais afetadas por esses fatores, que são as localizadas próximas das áreas de ressacas e de corpos hídricos.

Nos municípios, o Plano Diretor - PDM age como instrumento norteador para o ordenamento urbanístico e gestão das cidades, sendo obrigatório naqueles com mais de 20 mil habitantes (BRASIL, 2001). Em Macapá o PDM encontra-se defasado (produzido há 17anos, sem nenhuma atualização) e não considera devidamente os processos hidroclimáticos e fluvio-oceanográficos que influenciam a dinâmica da bacia do Igarapé da Fortaleza, dificultando a criação de legislação e órgãos institucionais (Itens 3, 9, 13 e 14 da tabela 3) destinados a trabalhos específicos na área de drenagem urbana e gestão das águas pluviais (PDMM, 2004; BASTOS, 2010). O PDM de Santana, apesar de atualizado, possui algumas deficiências quanto às informações das especificidades técnicas locais e organizações direcionadas propriamente para os problemas de 
drenagem como as inundações urbanas (PDMS, 2017).

A falta de educação ambiental e sanitária, principalmente em aglomerados subnormais, é um importante fator a ser pautado, pois em conjunto com a deficiência na coleta e manejo dos resíduos sólidos em Macapá e Santana, influencia na alta taxa de descarte de resíduos sólidos no sistema de micro e macrodrenagem (PMM, 2020; PMSB, 2016; SERRÃO et al., 2013). Como resultado é comum o entupimento de bueiros e obstruções de canais, que interfere diretamente no escoamento das águas e favorece a intensificação dos alagamentos que agravam problemas de outras dimensões (água, esgoto e resíduos sólidos) (Itens 4 e 5 da tabela 3 ). Os pontos de risco que indicam a preponderância destes problemas na figura 2, são os mais próximos de canais de drenagem.

Os escassos investimentos em projetos de drenagem urbana é um fator muito importante a ser considerado no trabalho, pois coopera para existência de sistemas obsoletos e deficitários, que já não são capazes de suprir a demanda (Itens 6,7 e 8 da tabela 3). Esta realidade não se restringe às cidades amapaenses, pois é também expandida para $25 \%$ dos municípios brasileiros que não fazem nenhuma manutenção nos seus sistemas de drenagem, diminuindo sua eficiência e aumentando o risco de alagamentos e inundações (SNIS, 2019).

Macapá e Santana são núcleos urbanos típicos do Amapá, com aspectos ambientais semelhantes, principalmente por fazerem parte da mesma bacia hidrográfica (BASTOS, 2010). Este vínculo hidráulico deve ser respeitado no gerenciamento, planejamento urbanístico e projetos de drenagem, para evitar danos futuros em grandes escalas envolvendo ambos os municípios. Essa importante correlação é considerada no plano diretor de Macapá, mas não é citado no de Santana, como observado no item 10 da tabela 3 (PDMM, 2004; PDMS, 2017).

Os impactos provenientes dos alagamentos e inundações podem ser intensificados pela ausência de banco de dados confiáveis sobre precipitação (Item 11 da tabela 3). A ausência de um banco de dados dificulta a tomada de decisão e estratégias de prevenção. Não é o caso de Macapá e Santana, que têm a disponibilidade de informações diretamente do Instituto Nacional de Meteorologia (INMET) e do Núcleo de Hidrometeorologia e Energias Renováveis (NHMET) (PMSB, 2016; IEPA, 2021). O fato preocupante não é a falta de dados, mas sim a forma ineficaz como está sendo utilizado. Como reflexo, as cidades não estão preparando a estrutura de gestão necessária para suportar eventos excepcionais como o ocorrido em Macapá, com dramáticos problemas que surgiram, principalmente os de caráter social e ambiental (SERRÃO et al., 2013; SOUSA et al., 2019).

Apesar das defesas civis de Macapá e Santana deterem o conhecimento meteorológico disponível (INMET), não é possível aplicar o mesmo padrão de gestão em ambas às cidades para o credenciamento de obras de drenagem (Item 12 da tabela 3), pois ainda há um déficit diferenciado de informações nessas áreas, dificultando a gestão do sistema de micro e macro drenagens, por exemplo (SOUSA et al., 2019).

Enfim, as informações integradas no mapa temático (Figura 2) e tabela explicativa (Tabela 3) oferecem uma primeira aproximação fornecendo uma visão mais holística das demandas do setor de gestão de águas pluviais e do sistema de drenagem integrado aos problemas sanitários e riscos preliminares de 
alagamento em Macapá e Santana. Esta abordagem permite, de forma inédita para o Estado do Amapá, um registro de alerta para o poder público que necessita elaborar novos subsídios estruturantes para o planejamento e gestão municipal do setor de saneamento básico nas capitais do Estado (por exemplo, atualização dos Planos Municipais de Saneamento Básico e Planos Diretores).

Com efeito, a presente pesquisa representa um cenário atual inédito da literatura regional, em que pese as duas principais cidades do Estado (Macapá e Santana), com uma contribuição básica frequentemente ausente, mas necessária para suprir as bases de dados dos sistemas públicos do setor no Estado do Amapá. Considerar esta dimensão no contexto sanitário é fundamental para o equilíbrio e a sustentabilidade da gestão dos ecossistemas urbanos no contexto de bacias hidrográficas (PROMINSKI et al., 2017; OLIVEIRA et al., 2019; DAMASCENO, et al., 2015).

\section{CONCLUSÕES}

As hipóteses da pesquisa foram confirmadas. Macapá e Santana são cidades já marcadas por setores de risco de alagamentos e inundações. Isso decorre de fatores como o modelo de urbanização acelerada e à falta de ordenamento territorial, presença de aglomerados subnormais e redução da qualidade sanitária dessas cidades, gerando o aumento do grau de risco aos alagamentos. Contribuem para o alto e médio grau de risco de alagamento a baixa eficiência do sistema de drenagem (quando existente) e fatores ambientais naturais e causados pela falta de gestão, onde os eventos tendem a ser intensificados.

Então, apesar dos núcleos urbanos de Macapá e Santana possuírem áreas territoriais e populações distintas, há similaridades nesses padrões de alagamentos, pois ambos apresentam elevada predominância de áreas de alto risco. Deste modo, há que se distinguir quais são fatores naturais e quais são os fatores antrópicos que influenciam no grau de risco ao alagamento. Observa-se que há similaridades físicas e geográficas (ambas as cidades estão na mesma bacia hidrográfica), mas há que se considerar o comportamento socioambiental das populações, que influencia diretamente na salubridade do ambiente (como é o caso dos resíduos sólidos que prejudicam o sistema de drenagem).

Portanto, até o momento, parece que a atenção governamental para esses eventos tem sido direcionada e focada sobre como remediar os impactos e não como preveni-los. Espera-se que esta pesquisa possa contribuir para o gerenciamento de risco municipal e planejamento estratégico das cidades de Macapá e Santana, auxiliando atuais e futuras ações e programas do setor, sem desconsiderar a importância das dimensões ambiental, sanitária e socioambiental que integra toda a problemática dos alagamentos urbanos na Amazônia.

\section{REFERÊNCIAS}

ABREU, C. H. M.; BARROS, M. L. C.; BRITO, D. C.; TEIXEIRA, M. R.; CUNHA, A. C.. Hydrodynamic modeling and simulation of water residence time in the estuary of the lower amazon river. Water, v.12, n.3, p.660-689, 2020. DOI:

http://dx.doi.org/10.3390/w12030660

ABU, M.; CODJOE, S. N. A.. Experience and Future Perceived
Risk of Floods and Diarrheal Disease in Urban Poor Communities in Accra, Ghana. International Journal of Environmental Research and Public Health, v.15, n.12, p.2830, 2018. DOI:

https://pubmed.ncbi.nIm.nih.gov/30545071/

ARAÚJO, A. C. R.; SANTOS, C. S.; GONÇALVES, J. R. M.R. 
análise da drenagem urbana com ênfase na redução de riscos de enchentes. Rev. Augustus, v.24, n.48, p.146-158, 2019. DOI:

https://doi.org/10.15202/1981896.2019v24n48p146

BARROS, M. T. L.. Drenagem urbana: bases conceituais e planejamento. In: PHILIPPI JUNIOR, A. Saneamento, Saúde e Ambiente: Fundamentos para um desenvolvimento sustentável. Barueri: EDUSP. 2005. p.221-266.

\section{BASTOS, M. A.. Modelagem de Escoamento Ambiental} como Subsídio à Gestão dos Ecossistemas Aquáticos no Baixo Igarapé da Fortaleza-AP. Dissertação (Mestrado em Biodiversidade Tropical) - Universidade Federal do Amapá, Macapá, 2010.

BATTEMARCO, B. P.; YAMAMOTO, L. M. T.; VERÓL, A. P.; REGO, A. Q.; VASCONCELLOS, V. M. N.; MIGUEZ, M. G.. Sistemas de Espaços Livres e Drenagem Urbana: Um Exemplo de Integração entre o Manejo Sustentável de Águas Pluviais e o Planejamento Urbano. Paisagem e Ambiente: Ensaios, São Paulo, n.42, p.55-74, 2018. DOI: http://www.revistas.usp.br/paam/article/view/145186/153 $\underline{018}$

BCDCA. Base Cartográfica Digital Contínua do Amapá. Governo do Estado do Amapá; Exército Brasileiro. 2015.

BOHNENBERGER, J. C.; CESAR JUNIOR, K. M. L.; CALIJURI, M. L.. Numerical modeling for the urban drainage gallery systems design. RBRH, v.24, e45, 2019. DOI: https://doi.org/10.1590/2318-0331.241920180172

BRASIL. Lei no 11.445 de 5 de Janeiro de 2007: Dispõe sobre as diretrizes do Saneamento Básico. Brasília: DOU, 2007.

BRASIL. Lei no 14.026, de 15 de Julho de 2020: Atualiza o marco legal do saneamento básico; e dá outras providências. Brasília: DOU, 2020.

BRASIL. Lei $n^{\circ}$ 10.257, de 10 de julho de 2001: Política Urbana. Brasília: DOU, 2001.

BRASIL. Mapeamento de Riscos em Encostas e Margem de Rios. Brasília: Ministério das Cidades; Instituto de Pesquisas Tecnológicas - IPT, 2007.

CANHOLI, A. P.. Drenagem Urbana e Controle de Enchentes. São Paulo: Oficina de Textos, 2005.

CEDEC. Coordenadoria Estadual de Defesa Civil. Dados sobre áreas de riscos a alagamentos. Macapá: CEDEC-AP, 2018.

CHAGAS, M. A.; SANTOS, J. S. A.; SILVA, E. L.. Política Ambiental: a Negligência do Urbano na Amazônia. PRACS: Revista Eletrônica de Humanidades do Curso de Ciências Sociais da UNIFAP, v.9, n.1, p.127-136, 2016. DOI: http://dx.doi.org/10.18468/pracs.2016v9n1.p127-136

CUNHA, A. C.; STERNBERG, L. S. L.. Using stable isotopes ${ }^{18} \mathrm{O}$ and ${ }^{2} \mathrm{H}$ of lake water and biogeochemical analysis to identify factors affecting water quality in four estuarine Amazonian shallow lakes. Hydrological Processes, v.32, p.1188-1201, 2018. DOI: http://dx.doi.org/10.1002/hyp.11462

DAMASCENO, M. C. S.; RIBEIRO, H. M. C.; TAKIYAMA, L. R.; PAULA, M. T.. Avaliação sazonal da qualidade das águas superficiais do Rio Amazonas na orla da cidade de Macapá, Amapá, Brasil. Ambiente e Água - An Interdisciplinary Journal of Applied Science, v.10, n.3, p.598-613, 2015. DOI: http://dx.doi.org/10.4136/ambi-agua.1606

GROTT, S. L.; FAÇANHA, E. B.; FURTADO, R. N.; CUNHA, H. F. A.; CUNHA, A. C.. Variação espaço-sazonal de parâmetros da qualidade da água subterrânea usada em consumo humano em Macapá, Amapá, Brasil. Engenharia Sanitária e Ambiental, v.23, n.4, p.645-654, 2018. DOI: http://dx.doi.org/10.1590/s1413-41522018162018

HORA, S. B.; GOMES, R. L.. Mapeamento e Avaliação do Risco a Inundação do Rio Cachoeira em Trecho da Área Urbana do Município de Itabuna/BA. Sociedade \& Natureza, Uberlândia, v.21, n.2, p.57-75, 2009.

IBGE. Instituto Brasileiro de Geografia e Estatística. Cidades e Estados. Macapá: IBGE, 2020.

IEPA. Instituto de Pesquisas Científicas e Tecnológicas do Estado do Amapá. Núcleo de Hidrometeorologia e Energias Renováveis. Macapá: IEPA, 2021.

LIMA, G. F.. Avaliação das Áreas de Risco de Inundação no Município de Pelotas, RS: Uma Proposta Metodológica. Monografia (Bacharelado em Engenharia Ambiental e Sanitária) - Universidade Federal de Pelotas, Pelotas, 2016.

LOURENÇO, T.; PRADO, R. B.. Índices de saneamento ambiental em regiões hidrográficas do estado do Rio de Janeiro. Revista de Gestão de Água da América Latina, v.16, e7, 2019. DOI: http://doi.org/10.21168/rega.v16e7

MANSUR, A. V.; BRONDIZIO, E. S.; ROY, S.; SOARES, A. M. P. P.; NEWTON, A.. Adapting to urban challenges in the Amazon: flood risk and infrastructure deficiencies in Belém, Brazil. Regional Environmental Change, v.18, p.1411-1426, 2018. DOI: https://doi.org/10.3390/w12051474

METRÓPOLES. Em meio a apagão, chuva mais intensa do ano causa alagamentos em Macapá. Macapá: METRÓPOLES, 2020.

MONTAGNA, T.; VIEIRA, R.. Infraestrutura de mobilidade urbana e sua articulação com a drenagem sustentável. Confins, v.43, 2019. DOI: https://doi.org/10.4000/confins.24654

MORAIS, T. O.; BASTOS, A. B.; SILVA, R. M. A.; BRITO, D. M. C.. Expansão urbana de Macapá, no Amapá: o caso da zona norte. Planeta Amazônia: Revista Internacional de Direito Ambiental e Políticas Públicas, n.10, p.91-101, 2018. DOI: http://dx.doi.org/10.18468/planetaamazonia.2018n10.p91$\underline{101}$

NUNES, A. A.; PINTO, E. J. A.; BAPTISTA, M. B.. Detection of trends for extreme events of precipitation in the Metropolitan Region of Belo Horizonte through statistical methods. RBRH, v.23, e9, 2018. DOI: https://doi.org/10.1590/2318-0331.0318170134

OLIVEIRA, E. D. C.; CUNHA, A. C.; SILVA, N. B. S.; CASTELOBRANCO, R.; MORAIS, J.; SCHNEIDER, M. P. C.; FAUSTINO, S. M. M.; RAMOS, V.; VASCONCELOS, V.. Morphological and molecular characterization of cyanobacterial isolates from the mouth of the Amazon River. Phytotaxa, v.387, n.4, 
p.269-288, 2019. DOI:

http://dx.doi.org/10.11646/phytotaxa.387.4.1

PDMM. Plano Diretor Municipal de Macapá. Macapá: Prefeitura Municipal de Macapá, 2004.

PDMS. Plano Diretor Municipal de Santana. Santana: Prefeitura Municipal de Santana, 2017

PMSB. Plano Municipal de Saneamento Básico de Macapá: Diagnóstico da Prestação dos Serviços de Saneamento Básico. Macapá: MPB Engenharia, 2016.

PMM. Prefeitura Municipal de Macapá. Prefeitura intensifica trabalho de desobstrução e limpeza em canais e bueiros para evitar alagamentos em período de chuva em Macapá. Macapá: PMM, 2020.

PIACENTINI, S. M.; ROSSETTO, R.. Attitude and Actual Behaviour towards Water-Related Green Infrastructures and Sustainable Drainage Systems in Four North-Western Mediterranean Regions of Italy and France. Water, v.12, p.1474, 2020. DOI: https://doi.org/10.3390/w12051474

PROMINSKI, M.; STOKMAN, A.; ZELLER, S.; STIMBERG, D.; VOERMANEK, H. B.. Rivers. Space. Design Planning Strategies, Methods and Project for Urban Rivers. Second and Enlarged. Basel: Birkhauser, 2017.

QGIS. Projeto QGIS. Sistemas de Informação Geográfica. QGIS, 2019.

ROCHA, L. L. L.; RIBEIRO, R. J. C.. Reservatórios de detenção e infiltração de águas pluviais: Uma análise sob a ótica urbana. Estudo de caso da cidade de Natal/RN. Cadernos de Arquitetura e Urbanismo, Paranoá 22, 2018. DOI: http://dx.doi.org/10.18830/issn.1679-0944.n22.2018.02

RODRIGUES, F. S.; LISTO, F. L. R.. Mapeamento de áreas de risco a escorregamentos e inundações em áreas marginais a rodovias na Região Metropolitana de São Paulo. Engenharia Sanitária Ambiental, v.21, n.4, 2016. DOI: https://doi.org/10.1590/s1413-41522016152649

SABÓIA, M. A. M.; SOUZA FILHO, F. A.; ARAUJO JUNIOR, L. M.; SILVEIRA, C. S.. Climate changes impact estimation on urban drainage system located in low latitudes districts: a study case in Fortaleza-CE. RBRH, v.22, e21, 2017. DOI: https://doi.org/10.1590/2318-0331.011716074 SANTOS, D. L.; SOUZA, V. C. B.; FRAGOSO JUNIOR, C. R. Limiar de precipitação com potencial de gerar deslizamentos nos complexos de risco em uma zona urbana. Revista de Gestão de Água da América Latina, v.16, e12, 2019. DOI: http://doi.org/10.21168/rega.v16e12
SANTOS, V. F.. Dinâmica de inundação em áreas úmidas costeiras: zona urbana de Macapá e Santana, costa amazônica, Amapá. PRACS: Revista Eletrônica de Humanidades do Curso de Ciências Sociais da UNIFAP, v.9, n.3, p.121-144, 2016. DOI:

http://dx.doi.org/10.18468/pracs.2016v9n3.p121-144

SERRÃO, S. L.; LIMA, R. A. P. .Áreas alagadas em Macapá: estudo de caso Bairro do Araxá. Biota Amazônia, v.3, n.3, p.146-156, 2013. DOI: http://dx.doi.org/10.18561/21795746/biotaamazonia.v3n3p146-156

SILVA JUNIOR, M. A. B.; SILVA, S. R.; CABRAL, J. J. S. P.. Compensatory alternatives for flooding control in urban areas with tidal influence in Recife - PE. RBRH, v.22, e19, 2017. DOI: https://doi.org/10.1590/2318-0331.011716040

SNIS. Sistema Nacional de Informações sobre Saneamento. 3o Diagnóstico de Drenagem e Manejo das Águas Pluviais Urbanas - 2018. Brasília: SNS/MDR, 2019.

SOUSA, T. S.; VIEGAS, C. J. T.; CUNHA, H. F. A.; CUNHA, A. C. Sistema de drenagem urbana no município de Macapá-AP como dimensão relevante do saneamento básico. In: SEMANA CIENTIFICA DE ENGENHARIA CIVIL DA UNIFAP, 1. Anais. Macapá, 2019.

TAKIYAMA, L. R.; SILVA, U. R. L.; JIMENEZ, E. A.; PEREIRA, R. A.; ZACARDI, D. M.; FERNANDES, E. F.; SOUTO, F. A. F.; SILVA, L. M. A.; SILVA, M. S.; SANTOS, M. A. C.; COSTA NETO, S. V.; SANTOS, V. F.. Projeto zoneamento ecológico econômico urbano das áreas de ressacas de Macapá e Santana, estado do Amapá: relatório final. Macapá: IEPA, 2012.

TEIXEIRA, D. A.; PRADO FILHO, J. F.; SANTIAGO, A. F.. Indicador de salubridade ambiental: variações da formulação e usos do indicador no Brasil. Engenharia Sanitária Ambiental, v.23, n.3, 2018. DOI: https://doi.org/10.1590/s1413-41522018170866

TZORTZIS, P. S.; KNIESS, C. T.. Programa de Despoluição de Córregos: Programa Córrego Limpo. Revista Inovação, Projetos e Tecnologias - IPTEC, v.4, n.1, 2016.

VIEGAS, C. J. T.; SOUSA, T. S.; CUNHA, H. F. A.; CUNHA, A. C. Sistema de esgotamento sanitário e casos de diarreia em Macapá-AP. Revista Ibero-americana de Ciências Ambientais, v.12, n.02, 2021.

ZUBELZU, S.; RODRIGUEZ-SINOBAS, L.; SORDO-WARD, A.; PEREZ-DURAN, A.; CISNEROS-ALMAZAN, R.. Multi-Objective Approach for Determining Optimal Sustainable Urban Drainage Systems Combination at City Scale. The Case of San Luis Potosí (México). Water, v.12, p.835, 2020. DOI: https://doi.org/10.3390/w12030835

A CBPC - Companhia Brasileira de Produção Científica (CNPJ: 11.221.422/0001-03) detém os direitos materiais desta publicação. Os direitos referem-se à publicação do trabalho em qualquer parte do mundo, incluindo os direitos às renovações, expansões e disseminacões da contribuicão, bem como outros direitos subsidiários. Todos os trabalhos publicados eletronicamente poderão posteriormente ser publicados em coletâneas impressas sob coordenação da Sustenere Publishing da Companhia Brasileira de Produção Científica e seus parceiros autorizados. Os (as) autores (as) posteriormente ser publicados em coletâneas impressas sob coordenação da Sustenere Publishing, da Companhia Brasileira de Produção Cientifica e seus parce 